\title{
Effect of Distiller's Dried Grains with Solubles (DDGS) Feeding to Dairy Cows on Oxidative Status under Hot Condition
}

\author{
Masahito TANAKA ${ }^{1 *}$, Tomoyuki SUZUKI ${ }^{1}$, Saber KOTB ${ }^{2}$ and Yuko KAMIYA ${ }^{1}$ \\ 1 Research Team for Effects of Climate Change on Agriculture, National Agricultural Research \\ Center for the Kyushu Okinawa Region, National Agriculture and Food research Organization \\ (Koshi, Kumamoto 861-1192, Japan) \\ 2 Faculty of Veterinary Medicine, Graduate School of Agricultural Science, Assiut University \\ (Assiut University, Egypt)
}

\begin{abstract}
Distiller's Dried Grains with Solubles (DDGS) derived from ethanol production with corn grains contained about 3 times more fat than the corn. The concentrated fat containing vitamin $\mathrm{E}$ and other components derived from the fermentation process is thought to possess an antioxidative function, although information about the antioxidative function of DDGS feeding to animals is limited, hence the effect of DDGS feeding of dairy cows on oxidative stress markers in plasma at high environmental temperatures was investigated. Six Holstein cows were divided into 2 groups, one of which was fed total mixed ration (TMR) including 20\%DM of DDGS, while another control group was fed similar TMR without DDGS for 17 days at a high environmental temperature. The dry matter intake in the DDGS group was similar to the control group. In the DDGS group, the milk protein content was lower and the milk lactose content higher than those of the control group (P < 0.05). Concentrations of SH residue and ascorbic acid in the plasma seemed higher in the DDGS group than the control, but not significantly. However, the concentration of thiobarbituric acid reactive substances in plasma was lower in the DDGS group than the control $(\mathrm{P}<0.05)$. DDGS feeding to cows might be effective in reducing oxidative stress during hot seasons.
\end{abstract}

Discipline: Animal industry

Additional key words: milk production, oxidative stress, Holstein cows

\section{Introduction}

It is known that distiller's dried grains with solubles (DDGS) is one of effective feedstuffs for dairy cows. Most Asian countries import DDGS as feedstuff from the U.S.A. and other countries. It was reported that feeding of DDGS at $15 \%$ in dry matter $(\mathrm{DM})^{7}$, $20 \% \mathrm{DM}^{8)}$ and $30 \% \mathrm{DM}^{6}$ to dairy cows presented no problems in terms of dairy management. DDGS are low in lignin and starch and high in digestible neutral detergent fiber ${ }^{3), 11)}$ compared with original corn grains. Besides, the DDGS contain higher protein and fat, which is rich in vitamin $\mathrm{E}$ with some variation in the production process $^{4}$. Vitamin E, as an oil-soluble vitamin, is considered effective to reduce the oxidative stress of dairy cows in hot conditions. One of the distiller's grain, distillation residue of Awamori spirit contains several antioxidative components, cyclic dipeptides, which shown reducing activity 0.89 to 4.2 times that of Lascorbic acid ${ }^{19}$. Oxidative stress in cows at higher ambient temperature was increased ${ }^{20)}$ and the milking performance in hot conditions shown a negative correlation with oxidative stress in dairy cows ${ }^{21)}$. Information on the influences of DDGS feeding to dairy cows in hot conditions on the oxidative status in cows is limited. The objectives of this study are to evaluate the antioxidative effect of DDGS feeding to dairy cows during the hot season on certain oxidative stress markers in plasma.

\section{Materials and methods}

Six Holstein cows (age $4.3 \pm 1.6$ year, parity $2.0 \pm$ $0.9)$ were divided into 2 groups, one of which was fed total mixed ration (TMR) (TDN=72.2\%DM, $\mathrm{CP}=14.4 \%$ DM) including 20\%DM of DDGS, another group was fed similar TMR $(\mathrm{TDN}=72.2 \% \mathrm{DM}, \quad \mathrm{CP}=14.4 \% \mathrm{DM})$ 
without DDGS for 17 days in summer. Each TMR was fed three times a day at 0900, 1300 and 1800. Every cow was fed in tie stool and cooled down by forced wind and periodical mist in day time, and could freely access water and feed. The ingredients of both TMR are shown in Table 1. The rectal temperature of each cow was recorded every morning after milking during the experimental period, while dry matter intake and milk production were recorded on 13th to 17th day after feeding. The milk yield was recorded using a WIKATO milk meter (Hamilton, New Zealand) during morning and evening milking times and the milk's fat $\%$, protein $\%$, lactose $\%$, and solid-non-fat (SNF)\% were measured by an automatic analyzer (Milko-Scan 133B; Foss Japan, Tokyo, Japan) on the 17th day. The concentration of sulfhydryl $(\mathrm{SH})$ residue in fresh plasma was determined using spectrophotometric methods employing dithionitrobenzene (DTNB) in a manner described previously ${ }^{10)}$. Tubes containing $2.7 \mathrm{~mL}$ of $0.2 \mathrm{M} \mathrm{Na} \mathrm{HPO}_{4}$ with $2 \mathrm{mM} \mathrm{Na} \mathrm{N}_{2}$ EDTA, $0.3 \mathrm{~mL}$ fresh plasma, and $60 \mu \mathrm{L}$ of $10 \mathrm{mM}$ DTNB in $0.2 \mathrm{M} \mathrm{Na} \mathrm{HPO}_{4}$ were incubated at room temperature for $5 \mathrm{~min}$. The mixture was then transferred to a cuvette, and the optical density was measured at $412 \mathrm{~nm}$ against an air blank. A calibration curve was produced using the reduced glutathione dissolved in $0.2 \mathrm{M} \mathrm{Na}_{2} \mathrm{HPO}_{4}$.

Total ascorbic acid concentration in the dairy cow's plasma was measured according to the method described in Omaye et al. ${ }^{15)}$ Ascorbic acid was oxidized by copper ions to form dehydroascorbic acid and diketogulonic acid, which reacted with 2,4-dinitrophenylhydrazine to form the derivative bis-2,4-dinitrophenylhydrazone. One $\mathrm{mL}$ of fresh plasma was mixed with $1.0 \mathrm{~mL}$

Table 1. Ingredient, chemical composition and total digestible nutrients of DDGS and control TMR

\begin{tabular}{lcc}
\hline \hline & DDGS TMR & Control TMR \\
\hline Corn silage & 35.5 & 35.5 \\
Italian reygrass silage & 18.0 & 18.0 \\
DDGS & 20.0 & - \\
Corn grain & 18.0 & 20.0 \\
Soy bean meal & 5.0 & 18.0 \\
Commercial concentrates & 3.5 & 8.5 \\
Dry matter & 49.0 & 48.9 \\
Total digestible nutrients & 72.2 & 72.3 \\
Crude protein & 14.4 & 14.5 \\
Crude fat & 5.2 & 3.5 \\
\hline
\end{tabular}

$\%$ in dry matter, a: $\%$ in fresh matter. of ice-cold $10 \%$ trichloroacetic acid solution. After centrifugation, $1.0 \mathrm{~mL}$ of the supernatant was recovered and mixed with $0.2 \mathrm{~mL}$ of 2,4-dinitrophenylhydrazine/ thiourea/copper solution. The mixed solution was then incubated for 4 hours at $38^{\circ} \mathrm{C}$, whereupon $1.5 \mathrm{~mL}$ of ice-cold $65 \% \mathrm{H}_{2} \mathrm{SO}_{4}$ was added. The absorbance of the solution was determined at $520 \mathrm{~nm}$ and a standard curve was made using several concentrations of sodium ascorbate.

As a breakdown product of lipid peroxidation, the thiobarbituric acid reactive substances (TBARS) concentration in the plasma was determined using methods according to previous reports ${ }^{1,14}$. The stock solution contained equal volumes of trichloroacetic acid $15 \%(\mathrm{w} / \mathrm{v})$ in $0.25 \mathrm{~N}$ hydrochloric acid and 2-thiobarbituric acid $0.37 \%$ (w/v) in $0.25 \mathrm{~N}$ hydrochloric acid. Fresh plasma of $1 \mathrm{ml}$ was mixed with $2 \mathrm{ml}$ of the stock reagent in a screw-capped tube and heated for $15 \mathrm{~min}$ in boiling water. After cooling in ice water, $3 \mathrm{ml}$ of the extraction solution contained pyridine and 1-buthanol (1:15) was added and mixed well. The precipitate was removed by centrifugation at $3000 \mathrm{rpm}$ for $10 \mathrm{~min}$ and absorbance of supernatant was measured at $532 \mathrm{~nm}$ against the extraction solution without plasma extracts. A standard curve was prepared with several concentrations of malondialdehyde and all the above reagents without plasma.

All procedures were performed in accordance with the guidelines for the care and use of laboratory animals of the National Agricultural Research Center for the Kyushu/Okinawa Region. The values obtained from each cow during the experimental period were expressed as the means \pm standard deviation (SD). Statistical analysis was performed using a general linear model (GLM) procedure in SPSS for Windows 16.0J. P-values below 0.05 in difference tests were considered statistically significant.

\section{Results and discussion}

The average values of ambient temperature and relative humidity during the experimental period were $29.4 \pm 2.7^{\circ} \mathrm{C}$ and $75.4 \pm 12.0 \%$, respectively. The rectal temperature of the cows during the experimental period was higher than normal in comfortable condition, showing $38.8 \pm 0.36^{\circ} \mathrm{C}$ in the DDGS group, and $39.2 \pm$ $0.56^{\circ} \mathrm{C}$ in the control group on the 17 th day, respectively. Although the rectal temperature in the control group was higher than the DDGS group, the difference was not significant. DDGS feeding did not affect the rectal temperature of dairy cows in hot conditions. Dry matter intake was also unaffected by DDGS TMR feed- 
ing (Table 2). The palatability of the TMR containing DDGS 20\%DM seemed similar to the control TMR. The result is supported by previous reports of DDGS $15 \% \mathrm{DM}^{7}$ and $20 \% \mathrm{DM}$ feeding to dairy cows ${ }^{8}$. However, Janicek et al. ${ }^{6}$ reported that the dry matter intake of the cows fed with DDGS increased linearly according to the DDGS content from $0 \% \mathrm{DM}$ to $30 \% \mathrm{DM}$ in feed. These findings showed no negative effect of DDGS feeding to dairy cows on dry matter intake containing up to $30 \%$ DM in feed.

Milk production in both groups before the experimental period showed no difference statistically, with values of $35.4 \pm 7.7 \mathrm{~kg}$ /day in the DDGS group and $33.3 \pm 4.7 \mathrm{~kg} /$ day in the control, respectively. Feeding of DDGS TMR seemed to increase milk production compared with the control group without being significant. NDF in DDGS is highly digestible ${ }^{3}$, with three times the fat content of corn grain, which might affect the digestible energy in the TMR, despite having similar values for the apparent calculated total digestible nutrients of both TMR. Besides, the lactose content in milk was increased in the DDGS group with statistically significant differences $(\mathrm{P}<0.05)$ (Table 3$)$. The results suggested that the nutritional energy level in the DDGS group might be higher than that in the control group, because the lactose level in milk revealed the energy status in cows ${ }^{17}$. Further investigation on the properties of rumen volatile fatty acids is needed to confirm the reason for this result. The milk fat content in the DDGS group was lower than that in the control group but not significantly (Table 3). Dietary fat can adversely affect fiber digestion ${ }^{22}$ and may contribute to decrease milk production $^{16}$. Our results showed a tendency for increased milk production and decreased milk fat, which might not show over content of fat in DDGS TMR. Milk protein concentration in the DDGS group milk was lower than that of the control $(\mathrm{P}<0.05)$, but not net production, although the crude protein level in both TMR was adjusted to the same level of $14.4 \%$. Nichols et al. ${ }^{12}$ reported that Lys was a first-limiting amino acid in milk protein synthesis when diets contained $20 \%$ of DDGS. Lys content was mainly lower in corn and this amino acid was most susceptible to heat damage during the process of making DDGS ${ }^{18}$. In our result, the decreased milk protein in the DDGS group might derive from the relatively lower content of Lys in DDGS TMR.

Oxidative stress in cells has been reported to increase under heat stress conditions ${ }^{2,9}$. It is known that dairy cows in hot conditions were exposed to highly oxidative stress conditions. The values of three oxidative stress markers in plasma just before the experimental period showed no differences between the DDGS and
Table 2. Effect of DDGS feeding on dry matter intake

\begin{tabular}{lc}
\hline \hline & Dry matter intake $(\mathrm{kg} /$ day/head $)$ \\
\hline DDGS group & $23.5 \pm 2.2$ \\
Control group & $22.2 \pm 1.9$ \\
\hline
\end{tabular}

Mean \pm SD. Dry matter intake was measured from 13 to 17 days after feeding.

Table 3. Effect of DDGS feeding on milking performance

\begin{tabular}{lcccc}
\hline \hline & $\begin{array}{c}\text { Milk }^{\mathrm{a}} \\
(\mathrm{kg} / \mathrm{day})\end{array}$ & $\begin{array}{c}\text { fat } \\
(\%)\end{array}$ & $\begin{array}{c}\text { protein } \\
(\%)\end{array}$ & $\begin{array}{c}\text { lactose } \\
(\%)\end{array}$ \\
\hline DDGS group & $39.2 \pm 7.6$ & $3.3 \pm 0.2$ & $2.8 \pm 0.1$ & $4.7 \pm 0.1^{*}$ \\
Control group & $33.2 \pm 4.5$ & $3.6 \pm 0.6$ & $3.1 \pm 0.2^{*}$ & $4.5 \pm 0.1$ \\
\hline
\end{tabular}

Mean \pm SD. a: Milk yield was obtained from 13 to 17 days after feeding. Milk components were measured on the 17 th day. $*$ : $\mathrm{P}<0.05$

Table 4. Effect of DDGS feeding on oxidative stress markers in cow plasma

\begin{tabular}{lccc}
\hline \hline & $\begin{array}{c}\mathrm{SH} \\
(\mu \mathrm{M})\end{array}$ & $\begin{array}{c}\text { Ascorbic acid } \\
(\mathrm{mg} / \mathrm{L})\end{array}$ & $\begin{array}{c}\text { TBARS } \\
(\mathrm{nM})\end{array}$ \\
\hline DDGS group & $446.8 \pm 19.8$ & $4.9 \pm 1.2$ & $57.2 \pm 6.2$ \\
Control group & $427.7 \pm 31.6$ & $4.5 \pm 1.0$ & $72.6 \pm 8.5^{*}$ \\
\hline
\end{tabular}

Mean \pm SD. Plasma was obtained on the 17 th day after feeding. *:P $<0.05$

control groups and the oxidative stress markers in cow plasma did not change drastically (Table 4). The $\mathrm{SH}$ residue and ascorbic acid concentration in plasma tend to be higher in the DDGS group than the control group, while the alteration of either compound in plasma can be considered an indicator of the oxidative stress status in cows $^{20}$. However, the concentration of TBARS as another oxidative stress marker ${ }^{13}$, especially the oxidized product of polyunsaturated fatty acid in plasma, was found to be significantly decreased in the DDGS group on the 17 th day $(\mathrm{P}<0.05)$. It was reported that oxidative stress increased TBARS ${ }^{5}$, and the cytotoxic effects of TBARS were well-known ${ }^{23}$. Taken together with these results, the DDGS TMR feeding to cows in hot conditions might reduce oxidative stress in cows. Increased oxidative stress in dairy cows at higher ambient temperature is associated with a decrease in milk productivity $^{21}$, hence feeding DDGS to dairy cows during the hot season might depress the decrease of milk production by controlling the oxidative stress status. 
Further investigations into the precise mechanisms of the antioxidative function in the DDGS feeding of dairy cows over longer periods are necessary.

\section{Conclusion}

TMR containing DDGS 20\%DM feeding to dairy cows in hot conditions did not significantly affect rectal temperature, dry matter intake, and milk production. In the DDGS group, milk protein decreased and milk lactose increased. Oxidative stress markers, especially TBARS concentration in plasma, were found to be decreased in the DDGS group on the 17th day, while other markers of SH residue and ascorbic acid concentration in plasma tended to increase in the DDGS group. DDGS feeding might be effective as an antioxidative feedstuff in higher environmental temperatures.

\section{References}

1. Chitra, K. C., Latchoumycandane, C. \& Mathur, P. P. (2003) Induction of oxidative stress by bisphenol A in the epididymal sperm of rats. Toxycology 185, 119127.

2. Flanagan, S. W., Moseley, P. L. \& Buettner, G. R. (1998) Increased flux of free radicals in cells subjected to hyperthermia: detection by electron paramagnetic resonance spin trapping. FEBS Lett., 431, 285-286.

3. Getachew, G. et al. (2004) Relationship between chemical composition, dry matter degradation and in vitro gas production of several ruminant feeds. Anim. Feed Sci. Technol., 11, 57-71.

4. Gibreel, A. et al. (2009) Fermentation of barley by using Saccharomyces cerevisiae: Examination of barley as a feedstock for bioethanol production and valueadded products. Appl. Environ. Micrbiol., 75, 13631372.

5. Halliwell, B. \& Chirico, S. (1993) Lipid peroxidation: its mechanism, measurement, and significance. Am. J. Clin. Nutr., 57, 715-724.

6. Janicek B. N. et al. (2008) The effect of feeding dried distillers grains plus solubles on milk production and excretion of urinary purine derivatives. J. Dairy Sci., 91, 3544-3553.

7. Kelzer J. M. et al. (2009) Effects of feeding three types of corn-milling coproducts on milk production and ruminal fermentation of lactating Holstein cattle. J. Dairy Sci., 92, 5120-5132.

8. Kleinschmit, D. H. et al. (2006) Evaluation of various sources of corn dried distillers grain plus solubles for lactating dairy cattle. J. Dairy Sci., 89, 4784-4794.

9. Loven, D. P. (1988) A role for reduced oxygen species in heat induced killing and the induction of thermotolerance. Med. Hypotheses, 26, 39-50.

10. Motchnik, P. A., Frei, B. \& Ames, N. (1994) Measurement of antioxidants in human blood plasma. Meth. Enzymol., 234, 269-279.

11. National Research Council (2001) Nutrient Requirements of Dairy cattle. 7th rev. ed. Natl. Acad. Sci., Washington, DC.

12. Nichols, J. R. et al. (1998) Evaluation of corn distillers grains and ruminally protected lysine and methionine for lactating dairy cows. J. Dairy Sci., 81, 482-491.

13. Nielsen, F. et al. (1997) Plasma malondialdehyde as biomarker for oxidative stress: reference interval and effects of lifestyle factors. Clin. Chem., 43, 1209-1214.

14. Ohkawa, H., Ohnishi, N. \& Yagi, K. (1979) Assay for lipid peroxidation in animal tissues by thiobarbituric acid reaction. Anal. Chem., 95, 351-358

15. Omaye, S. T., Turnbull, J. D. \& Sauberlich, H. E. (1979) Selected methods for the determination of ascorbic acid in animal cells, Tissues, and fluids. Meth. Enzymol., 62, 3-11.

16. Pantoja, et al. (1994) Effects of saturation and source of fiber on site of nutrient digestion and milk production by lactating dairy cows. J. Dairy Sci., 77, 23412356.

17. Reist, M. D. et al. (2002) Estimation of energy balance at the individual and herd level using blood and milk traits in high-yielding dairy cows. J. Dairy Sci., 85, 3314-3327.

18. Schwab, C. G. (1995) Protected proteins and amino acids for ruminants. In Biotechnology in Animal Feeds and Animal Feeding. Wallace R. J. \& Chesson A. ed. VCH Press, Weinheim, Germany, 115-141.

19. Takaya, Y. et al.(2007) Antioxidant constituents in distillation residue of Awamori spirits. J. Agrc. Food Chem., 55, 75-79.

20. Tanaka, M. et al. (2007) Effect of high environmental temperature on ascorbic acid, sulfhydryl residue and oxidized lipid concentration in plasma of dairy cows. Anim. Sci. J., 78, 301-306.

21. Tanaka, M. et al. (2008) Relationship between milk production and plasma concentrations of oxidative stress markers at hot season in primiparous cows. Anim. Sci. J., 79, 481-486.

22. Van Soest, P. J. (1994) Nutritional ecology of the ruminant. $2^{\text {nd }}$ ed. Cornell University Press, Ithaca, NY, 292 $-296$.

23. Zollner H., Schaur, R. J. \& Esterbauer, H. (1991) Biological activities of 4-hydroxyalkenals. In Oxidative stress: Oxidants and Antioxidants, Academic Press, San Diego, CA, 337-397. 